\title{
Clinical Events Supplemental Qualifiers Dataset
}

National Cancer Institute

\section{Source}

National Cancer Institute. Clinical Events Supplemental Qualifiers Dataset. NCI

Thesaurus. Code C147191.

A dataset containing supplemental information, specifically non-standard variables, to parent records in the clinical events domain. 